\title{
INTERNATIONAL NETWORK FOR CAPACITY BUILDING FOR THE CONTROL OF EMERGING VIRAL VECTOR-BORNE ZOONOTIC DISEASES : ARBO-ZOONET
}

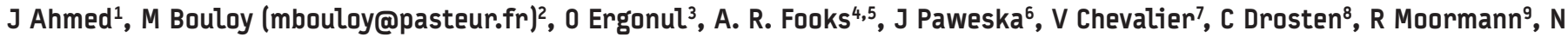 \\ Tordo $^{10}$, Z Vatansever ${ }^{11}$, P Calistri ${ }^{12}$, A Estrada-Peña ${ }^{13}$, A Mirazimi ${ }^{14}$, H Unger ${ }^{15}$, H Yin ${ }^{16}$, U Seitzer ${ }^{1}$ \\ 1. Veterinary Infection Biology and Immunology, Research Center Borstel, Borstel, Germany \\ 2. Molecular Genetics of Bunyaviruses, Institut Pasteur, Paris, France \\ 3. Marmara University Medical School Hospital, Istanbul, Turkey \\ 4. Virology Department, Veterinary Laboratories Agency - Weybridge, United Kingdom \\ 5. National Centre for Zoonoses, University of Liverpool, United Kingdom \\ 6. Special Pathogen Unit, National Institute for Communicable Diseases of the National Health Laboratory Service, \\ Gauteng, South Africa \\ 7. CIRAD-Département "Environments \& Societies" UR AGIRs “Animal and Integrated Risk management”, Montpellier, France \\ 8. Institute of Virology, University of Bonn Medical Centre, Bonn, Germany \\ 9. Division of infectious diseases, Central Veterinary Institute, Animal Sciences Group, Wageningen UR, \\ Lelystad, The Netherlands \\ 10. Biology of viral emerging infections, Institut Pasteur, Paris, France \\ 11. Kafkas University, Faculty of Veterinary Medicine, Dept. of Parasitology, Kars, Turkey \\ 12. Abruzzo and Molise Region Experimental Animal Health Care Institute"G. Caporale”, Teramo, Italy \\ 13. Department of Parasitology, Veterinary Faculty, Universidad de Zaragoza, Zaragoza, Spain \\ 14. Virology Unit, Centre for Microbiological Preparedness, Swedish Institute for Infectious Disease Control, Solna, Sweden \\ 15. Animal Production and Health, Joint FAO/IAEA Division of Nuclear Techniques in Food and Agriculture, International \\ Atomic Energy Agency, Vienna, Austria \\ 16. Lanzhou Veterinary Research Institute, Chinese Academy of Agricultural Sciences, Lanzhou, Gansu, China
}

\begin{abstract}
Arboviruses are arthropod-borne viruses, which include West Nile fever virus (WNFV), a mosquito-borne virus, Rift Valley fever virus (RVFV), a mosquito-borne virus, and Crimean-Congo haemorrhagic fever virus (CCHFV), a tick-borne virus. These arthropod-borne viruses can cause disease in different domestic and wild animals and in humans, posing a threat to public health because of their epidemic and zoonotic potential. In recent decades, the geographical distribution of these diseases has expanded. Outbreaks of WNF have already occurred in Europe, especially in the Mediterranean basin. Moreover, CCHF is endemic in many European countries and serious outbreaks have occurred, particularly in the Balkans, Turkey and Southern Federal Districts of Russia. In 2000, RVF was reported for the first time outside the African continent, with cases being confirmed in Saudi Arabia and Yemen. This spread was probably caused by ruminant trade and highlights that there is a threat of expansion of the virus into other parts of Asia and Europe. In the light of global warming and globalisation of trade and travel, public interest in emerging zoonotic diseases has increased. This is especially evident regarding the geographical spread of vectorborne diseases. A multi-disciplinary approach is now imperative, and groups need to collaborate in an integrated manner that includes vector control, vaccination programmes, improved therapy strategies, diagnostic tools and surveillance, public awareness, capacity building and improvement of infrastructure in endemic regions.
\end{abstract}

\section{Concept and objectives}

West Nile fever virus (WNFV), Rift Valley fever virus (RVFV) and Crimean-Congo haemorrhagic fever virus (CCHFV) are arthropodborne viruses that infect different domestic and wild animals and can also cause disease in humans [1-3]. Their geographical distribution has expanded over recent decades. WNF outbreaks have already occurred in Europe (Romania, Bulgaria, Italy and France) [4-6]. CCHF is endemic in many countries in Africa, Europe and Asia, and since 1999, cases or outbreaks have been recorded in Kosovo [7], Albania [8], Bulgaria [9], Greece [10], Iran, Pakistan, South Africa, and the Southern Federal Districts of Russia [11] as well as in Turkey [12-14]. RVF is present in a number of African countries. In September 2000, RVF was reported for the first time outside the African continent. Since then, cases have been confirmed in Saudi Arabia and Yemen [15]. This introduction of the epidemic to the Arabian Peninsula highlights that there is a threat of expansion into other parts of Asia and Europe. In 2007, an outbreak of RFV occurred in Kenya, Somalia and Tanzania and has recently expanded to Madagascar and South Africa in 2008 $[16,17]$.

There is a public interest regarding emerging zoonotic diseases and information is required to explain the presence of "disease hot- 
spots" in Europe. It is therefore imperative to work out integrated control measures which include:

- Vector control, including surveillance of naturally occurring vector populations and their suitability for transmission,

- Vaccination programmes,

- Improved therapy strategies,

- Improvement of diagnostic tools and surveillance,

- Public awareness campaigns,

- Capacity building and improvement of infrastructure in endemic regions.

The recent CCHF outbreak in Turkey is of particular interest. It was first recognised as an outbreak with thirteen cases in 2002. The total number of confirmed cases has since risen to 2,974 (reported between 2002 and 2008), including 146 deaths [12,13]. Although the exact data are not available, a similar situation is seen in the Southern Federal Districts of Russia, where the outbreak started in 1999. In response to this situation, the European Commission has included issues related to these diseases in its framework programme 7 (FP 7). In addition, the recent outbreaks of $\mathrm{CCHF}$ have prompted the World Health Organization (WHO) to take action in the form of a "Joint WHO-MZCP Intercountry Workshop on Crimean-Congo Haemorrhagic fever (CCHF) Prevention and Control", jointly organised by the Mediterranean Zoonoses Control Programme (MZCP), the Eastern Mediterranean Regional Office (EMRO), the Regional Office for Europe and the WHO headquarters, in collaboration with the World Organisation for Animal Health (OIE), the Food and Agriculture Organization of the United Nations (FAO/UN) and the Integrated Consortium on Ticks and Tick-borne Diseases (ICTTD-3). The workshop was held in Istanbul, Turkey on 6-8 November 2006. The meeting recognised that "CCHF outbreaks constitute a threat to public health services because of their epidemic potential, its high case fatality rate (5-40\%), its potential for nosocomial outbreaks and the difficulties in treatment and prevention".

During a meeting on RVFV, held by the Atomic Energy Agency in Nairobi on 5-9 March 2007, scientific representatives from African countries and Yemen, where the virus circulates, shared information and data on RVF surveillance.

Until the end of the 1990s, WNF was considered a minor risk to human health as the virus appeared only sporadically. Since 1996, the year of the first large outbreak in Romania [18], WNFV has become a major public health and veterinary concern in Europe and in the Mediterranean Basin, because new endemic foci have appeared. In the United States, an epidemic was first noted in New York City in 1999. Since then, more than 25,000 human cases and more than 15,000 equine cases have been reported [19]. In France, WNFV outbreaks occurred in 2000 (76 cases and 21 deaths in horses), 2003 (seven human cases and seven equine cases), 2004 (32 equine cases) and 2006 (five equine cases). In 2008, the first indigenous human WNFV cases were reported in Italy [20], and an increased number of cases was observed in the same year in Hungary [21]. In this context, there is an urgent need to improve serological tests and molecular tools for the rapid diagnosis of WNFV.

To this end, the ARBO-ZOONET project specifically promotes:

- Sharing knowledge of these diseases, exchanging data and expertise, improving the flow of scientific information,
- Maintaining and expanding surveillance systems, monitoring disease occurrence, virus isolation and vaccine use,

- Introducing and distributing tools for disease detection and control; creating common standards,

- Disseminating knowledge and organising training for staff of international organisations and relevant countries outside the European Union (EU), in particular those where these diseases represent a major threat to the EU as well as those that are particularly active in research,

- Interlinking different scientific disciplines.

\section{Work plan}

The work plan of ARBO-ZOONET foresees a number of interrelated tasks, with measurable deliverables and milestones. Specifically, the plan aims at:

1. Identifying risk areas and undertaking the necessary preparatory work for updated risk maps on RVF, WNF and CCHF introduction and/or spread throughout the EU territory. Efforts will focus on understanding the ecology of host, vectors and disease reservoir. Moreover, this task will produce maps and estimate the numbers of vectors in order to prepare models for policy makers.

2. Collection and preservation of biologically diverse pathogens is an essential pre-requisite for the improvement and harmonisation of diagnostic tests as well as for vaccine design. In addition, the availability of pure pathogen material is essential for the molecular characterisation of different isolates including their sequence and determination of pathogenicity and virulence. The establishment of pathogen bank facilities at regional reference laboratories is urgently required. This co-ordinated action will create a pathogen database open to the scientific community that will contain information on where live samples of a given pathogen are available. This database will include other biological material such as serum and genetic material from different geographical areas where the relevant diseases are endemic.

3. Surveillance networks will be established for the collection of global data on the occurrence of RVF, WNF and CCHF. An essential task of this project is reporting on the analysis of the RVF, WNF and CCHF surveillance systems for the EU and for affected areas in countries outside the EU. These analyses will be used to establish adequate georeferenced data and to derive spatial conclusions. The assessment will address significant aspects of the surveillance and control activities (monitoring approaches, diagnostic methods and capabilities, established information systems, data analysis capabilities, geographic distribution of virus strains, vector competence studies, entomological expertise and surveillance methods applied, protocols for vaccine use) to serve as a framework for shared datasets.

4.Moreover, working groups will be established to assess data focused on vector control, vaccination and therapy. The proposed project will act as a platform to bring together those participants who are actively involved in molecular vaccine development. Emphasis will be given to integrated vaccine strategies using vaccines based on pathogen and vector components and development of appropriate delivery systems. In this context, studies on molecular characterisation the interaction between host, vector and pathogen will be promoted, primarily through scientific exchange visits. Therapeutic options will also be examined. This will be done either by working on existing pharmaceuticals or by developing new ones.

5. The principal focus of the project is the transfer of knowledge and technology between the members of the consortium, which includes partners from relevant countries outside the EU. In this context, links will be established to the national and international 
organisations (WHO, FAO, OIE, or the International Regional Organization for Plant and Animal Health (OIRSA)), institutions and laboratories located in the different areas in order to disseminate and transfer technologies needed to develop strategies for integrated control measures in endemic regions such as diagnostics, epidemiology and economic dimension of a number of endemic as well as epizootic animal diseases.

6. ARBO-ZOONET will play a co-ordinating role a within the EU's Animal Health Strategy by bringing together interested members of other EU consortia that share the focus on zoonoses caused by vector-borne arboviruses, such as the Emerging Diseases in a changing European eNvironment (EDEN) project, the Network of Excellence for Epizootic Disease Diagnosis and Control (Epizone), and the Environmental Vulnerability Assessment (EVA) project.
The strategy of technology transfer (see Figure) is to train the staff in the use of tools and technologies required for:

- Specific and effective detection and differentiation of the pathogens causing the above diseases,

- Professional epidemiological studies,

- Effective control strategies, and

- Better disease outbreak management.

As a first step, pre-educated staff from countries outside the EU will be selected to be trained as trainers in different EU laboratories specialised in viral diseases, especially in those that have been recognised by the WHO as reference laboratories based on the availability of knowledge and the required infrastructure. As a second step, these trainers will then organise training courses in

F I G U R E

Overall strategy of the ARBO-ZOONET project

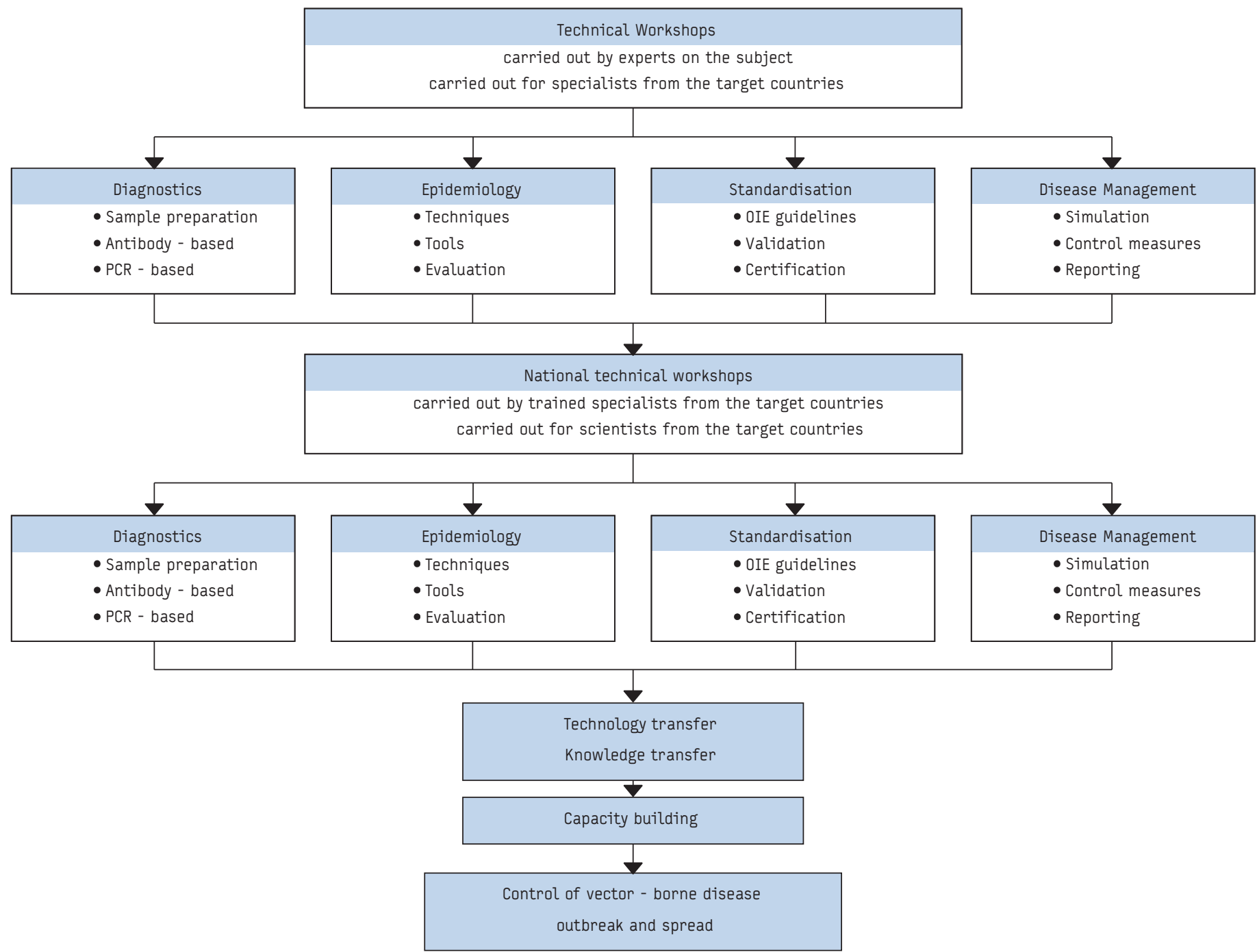

OIE: World Organisation for Animal Health 
their own countries in close cooperation and coordination with task forces to be established for this purpose.

The ARBO-ZOONET project is well integrated in international cooperating networks. In this context, joint meetings and activities in the field of disease surveillance and monitoring will be organised and the project will seek to cooperate with the European Centre for Disease Prevention and Control (ECDC) in this.

\section{Conclusions}

The project deals with three viruses considered to be emerging in Europe, although it is established that other arboviruses are also emerging. Knowledge gained in the course of this project may thus be relevant for other diseases and will be transferred to other networks dealing with these. In addition, experts on other vectorborne diseases will be invited to participate in ARBO-ZOONET activities.

An important aspect of this project will be that human and veterinary health authorities as well as veterinary education centres and faculties will work together in order to achieve the goals of the technology transfer.

\section{Aknowledgements}

Vivamus tempor mi quis quam. Fusce tempus, ante sed tincidunt ornare, nisi urna viverra enim, eget venenatis dui ante ut eros.

\section{References}

1. Blitvich BJ. Transmission dynamics and changing epidemiology of West Nile virus. Anim Health Res Rev. 2008;9(1):71-86.

2. Flick R, Bouloy M. Rift Valley fever virus. Curr Mol Med. 2005;5(8):827-34.

3. Ergönül 0. Crimean-Congo haemorrhagic fever. Lancet Infect Dis. 2006;6(4):203-14

4. Savage HM, Ceianu C, Nicolescu G, Karabatsos N, Lanciotti R, Vladimirescu $A$, et al. Entomologic and avian investigations of an epidemic of West Nile fever in Romania in 1996, with serologic and molecular characterization of a virus isolate from mosquitoes. Am J Trop Med Hyg. 1999;61(4):600-11

5. Durand B, Chevalier V, Pouillot R, Labie J, Marendat I, Murgue B, et al. West Nile virus outbreak in horses, southern France, 2000: results of a serosurvey. Emerg Infect Dis. 2002;8(8):777-82.

6. Autorino GL, Battisti A, Deubel V, Ferrari G, Forletta R, Giovannini A, et al. West Nile virus epidemic in horses, Tuscany region, Italy. Emerg Infect Dis. 2002;8(12):1372-8.

7. Ahmeti S, Raka L. Crimean-Congo haemorrhagic fever in Kosova: a fatal case report. Virol J. 2006;3:85.

8. Papa A, Bino S, Llagami A, Brahimaj B, Papadimitriou E, Pavlidou V, et al. Crimean-Congo hemorrhagic fever in Albania, 2001. Eur J Clin Microbiol Infect Dis. 2002;21(8):603-6.

9. Kunchev A, Kojouharova M. Probable cases of Crimean-Congo-haemorrhagic fever in Bulgaria: a preliminary report. Euro Surveill. 2008;13(17):pii=18845. Available from: http://www.eurosurveillance.org/ViewArticle. aspx?ArticleId $=18845$

10. Papa A, Maltezou HC, Tsiodras S, Dalla VG, Papadimitriou T, Pierroutsakos I, et al. A case of Crimean-Congo haemorrhagic fever in Greece, June 2008. Euro Surveill. 2008;13(33):pii=18952. Available from: http://www.eurosurveillance. org/ViewArticle.aspx?ArticleId=18952

11. Butenko AM, Korganova GG. Crimean-Congo Hemorrhagic Fever in Russia and Other Countries of the Former Soviet Union. In: 0 Ergonul,C Whitehouse, editors. Crimean-Congo Haemorrhagic Fever, A Global Perspective. Dordrecht: Springer; 2007. p.99-114.

12. Yilmaz GR, Buzgan T, Torunoglu MA, Safran A, Irmak H, Com S, et al. A preliminary report on Crimean-Congo haemorrhagic fever in Turkey, March June 2008. Euro Surveill. 2008;13(33):pii=18953. Available from: http://www. eurosurveillance.org/ViewArticle.aspx?ArticleId $=18953$

13. Ergonul 0. The Role of ARBO-ZOONET in Crimean-Congo Hemorrhagic Fever ARBO-ZOONET News 2009;2:5-6.
14. Estrada-Peña A, Zatansever Z, Gargili A, Aktas M, Uzun R, Ergonul O, et al. Modeling the spatial distribution of crimean-congo hemorrhagic fever outbreaks in Turkey. Vector Borne Zoonotic Dis. 2007;7(4):667-78.

15. Abdo-Salem S, Gerbier G, Bonnet P, Al-Qadasi M, Tran A, Thiry E, et al. Descriptive and spatial epidemiology of Rift valley fever outbreak in Yemen 2000-2001. Ann N Y Acad Sci. 2006;1081:240-2.

16. Bird BH, Githinji JW, Macharia JM, Kasiiti JL, Muriithi RM, Gacheru SG, et al. Multiple virus lineages sharing recent common ancestry were associated with a large Rift Valley fever outbreak among livestock in Kenya during 2006-2007. J Virol. 2008;82(22):11152-66.

17. Paweska J, Blumberg L, Weyer J, Kemp A, Leman P, Archer B, et al. Rift Valley fever outbreak in South Africa, 2008. NICD-NHLS Communicable Diseases Surveillance Bulletin.2008;6(2):1-2.

18. Campbell GL, Ceianu CS, Savage HM. Epidemic West Nile encephalitis in Romania: waiting for history to repeat itself. Ann N Y Acad Sci. 2001;951:94-101.

19. Zeller HG, Schuffenecker I. West Nile virus: an overview of its spread in Europe and the Mediterranean basin in contrast to its spread in the Americas. Eur J Clin Microbiol Infect Dis. 2004;23(3):147-56.

20. Rossini G, Cavrini F, Pierro A, Macini P, Finarelli A, Po C, et.al. First human case of West Nile virus neuroinvasive infection in Italy, September 2008 case report. Euro Surveill. 2008;13(41). pii: 19002. Available from: http://www. eurosurveillance.org/ViewArticle. aspx?ArticleId $=19002$

21. Krisztalovics K, Ferenczi E, Molnár Z, Csohán Á, Bán E, Zöldi V, et al. West Nile virus infections in Hungary, August-September 2008. Euro Surveill. 2008;13(45):pii: 19030. Available from: http://www.eurosurveillance.org/ ViewArticle.aspx?ArticleId $=19030$

This article was published on 26 March 2009.

Citation style for this article: Ahmed J, Bouloy M, Ergonul 0, Fooks AR, Paweska J, Chevalier V, Drosten C, Moormann R, Tordo N, Vatansever Z, Calistri P, Estrada-Peña $A$, Mirazimi A, Unger $H$, Yin $H$, Seitzer U. International network for capacity building for the control of emerging viral vector-borne zoonotic diseases: ARBO-ZOONET. Euro Surveill. 2009;14(12):pij=19160. Available online: http://www.eurosurveillance.org/ ViewArticle.aspx?ArticleId $=19160$ 